\title{
La lectura fácil: una apuesta de valor para las organizaciones ${ }^{1}$
}

\section{Easy to read: A commitment of value for organizations}

\section{Palabras clave}

Accesibilidad cognitiva, barreras, comprensión, igualdad, dignidad personal, ciudadanía.

\section{Keywords}

Cognitive accessibility barriers, understanding, equality, personal dignity, citizenship.

\author{
Jorge M. Pérez García \\ <jmperez@cuartosector.coop> \\ Instituto de Lectura Fácil
}

\section{Laura López de la Cruz}

$<$ <lopcru@upo.es>

Este artículo explica lo que es la lectura fácil.

Hay muchas personas en el mundo que no entienden lo que leen.

La lectura fácil es una forma especial de escribir textos y mensajes.

Todas las personas entienden los textos escritos en lectura fácil.

La lectura fácil es una forma de superar las barreras de comprensión que tienen muchas personas. Las organizaciones ayudan a comprender los textos cuando escriben sus mensajes en lectura fácil.
Universidad Pablo de Olavide

\section{Para citar:}

Pérez, J.M y López, L. (20I 5): "La lectura fácil: una apuesta de valor para las organizaciones”, Revista Española de Discapacidad, 3 (I): I87-I92.

Doi: <http://dx.doi.org/IO.5569/23405IO4.03.OI.IO> 
El mandato constitucional de que la dignidad de la persona sea considerada como un pilar básico sobre el que se asienta nuestro ordenamiento jurídico, que se tengan en cuenta los derechos que le son inherentes y el libre desarrollo de la personalidad y que las condiciones de igualdad y libertad sean reales y efectivas (art. Io CE) exige a los poderes públicos la adopción de una serie de medidas dirigidas a remover los obstáculos que en la vida diaria efectivamente impiden a unos ciudadanos las mismas cotas de bienestar y el acceso a determinados servicios públicos y privados en las mismas condiciones que otros.

En efecto, podríamos hacer referencia a determinadas condiciones y circunstancias que afectan a la persona, que no han sido tradicionalmente identificadas ni reconocidas dentro del concepto jurídico de estados civiles, pero que son comunes a distintos colectivos y suponen un condicionamiento a la hora de ejercitar sus derechos de ciudadanía, entendida esta en sentido amplio.

Desde esta perspectiva, en el ámbito propio del Derecho de la persona, algunos autores comienzan a hablar de un nuevo estatuto jurídico al que denominan "condiciones civiles emergentes", y que se refiere a aquellas cualidades y situaciones personales que afectan a los sujetos de derecho, tomadas en cuenta por la norma para garantizar el libre desarrollo de la personalidad, que procuran a la persona un estatuto jurídico diferenciado del ordinario, generalmente de índole mixta" (Gete-Alonso y Calera, 20I3; p. 223). Es decir, se toman en consideración circunstancias y situaciones que afectan a la persona en el desarrollo de su vida diaria, que hasta ahora no se habían estudiado como un conjunto de situaciones generales y de aplicación amplia, que condicionan la vida en sociedad en igualdad de condiciones respecto del resto de ciudadanos y ciudadanas.

Entre estas circunstancias y situaciones personales se alude a la dependencia física derivada de la edad, limitaciones sensoriales, la alteración de las capacidades cognitivas por diversos motivos (edad, accidente o enfermedad, discapacidad), dificultades en el aprendizaje por experiencias vitales de distinta índole (escasa formación, inmigrantes), etc. Es decir, se trata de condiciones personales e individuales que afectan o son comunes a grupos amplios de personas y con un marcado carácter de permanencia que justifican la puesta en marcha de políticas públicas y el desarrollo de proyectos destinados a la plena integración de estas personas en la sociedad.

Cierto es que el legislador, tanto autonómico como estatal, está teniendo en cuenta estas nuevas realidades emergentes, lo que se ha reflejado en la promulgación de normas especiales y en la puesta en marcha de iniciativas cuya finalidad perseguida es garantizar los derechos de los colectivos más vulnerables o desfavorecidos. Así, podemos citar como ejemplos, en materia de dependencia, la Ley 39/2006, de I4 de diciembre, de promoción de la autonomía personal y atención a las personas en situación de dependencia; respecto a las personas con discapacidad, la Ley 4I/2003, de I 8 de noviembre, de protección patrimonial de las personas con discapacidad y de modificación del Código Civil, de la Ley de Enjuiciamiento Civil y de la normativa tributaria con esta finalidad; sobre acogimiento de personas mayores: la Ley 22/2000, de 29 de diciembre, de acogida de personas mayores, de Cataluña o la Ley foral 34/2002, de ro de diciembre, de acogimiento familiar de personas mayores, de Navarra.

En concreto, si atendemos a las situaciones de discapacidad, tradicionalmente las administraciones han priorizado la accesibilidad como medio más efectivo de lograr la igualdad de oportunidades. Sin embargo, llama la atención que las iniciativas de impulso de la accesibilidad tienden de modo sistemático a ignorar la discapacidad cognitiva (véase por ejemplo el Plan de Accesibilidad 2003-2010 del Ministerio de Trabajo y Asuntos Sociales). La explicación de esta laguna es diversa y no es ajena al hecho de que esta discapacidad incluye un enorme y amplísimo número de disfunciones que la hacen difícil de definir y categorizar (Verdugo, 2003) y por ende de visualizar en términos de accesibilidad. La discapacidad 
cognitiva se asocia a trastornos conductuales o de personalidad, o a alteraciones de diverso tipo (cromosómicas, neurológicas, trastornos cerebrales...) que derivan en una disminución de las funciones mentales superiores (inteligencia, lenguaje, pensamiento...) y que condicionan las posibilidades del sujeto de asimilar y comprender la información compleja que recibe desde distintos medios, especialmente cuando esta se presenta en formato escrito.

Pero estas dificultades de comprensión no sólo afectan a personas con un grado mayor o menor de discapacidad, también a personas que por sus circunstancias vitales, y dentro de estas condiciones civiles emergentes a la que hemos hecho referencia, no tienen un fácil acceso a la información escrita. Entre ellas, cabe citar a colectivos de inmigrantes que deben familiarizarse por primera vez con la lengua española o aquellas personas que por su escaso nivel formativo no comprende o asimila fácilmente los mensajes escritos que reciben (analfabetos funcionales).

El acceso a la lectura representa un combinado de funciones mentales muy diversas, que van desde la capacidad para prestar atención, a la abstracción que representan los signos de la escritura. La lectura moviliza por igual al lenguaje natural y al pensamiento abstracto. Por lo tanto, cualquier disfunción que afecta a la lectura distorsiona la capacidad para desenvolverse en un mundo constituido por signos, desde los meros iconos hasta la escritura propiamente dicha. De hecho, se podría afirmar que ser analfabeto en la sociedad actual tal vez represente un handicap mucho más grave que una determinada limitación física o un trastorno neurológico, ya que la realidad cotidiana en que nos desenvolvemos es de una alta densidad semiótica (iconos, textos, anuncios, emoticones, etc.).

Como consecuencia, la dificultad para acceder plenamente a la información escrita puede convertirse en una fuente de desigualdad e incluso de desprotección de estos colectivos. La limitación al acceso a recursos públicos, a la cultura, a información relevante en la vida cotidiana, en definitiva puede suponer una enorme barrera que impida la participación efectiva en la sociedad. Por todo ello, se requieren iniciativas y proyectos que proporcionen a todas estas personas a las que se ha hecho referencia las herramientas necesarias para eliminar las barreras de la comprensión en un mundo condicionado y regido por el lenguaje escrito.

Y es en este contexto donde surge la iniciativa de la Lectura Fácil (IFLA, 20I0), que se presenta como un medio de proporcionar accesibilidad en un mundo crecientemente literario, basado en textos. Reconociendo este hecho, la iniciativa que promueve la Lectura Fácil trasciende al propio concepto de discapacidad para extenderse a aquel sector de la población no plenamente alfabetizado o a aquellos ámbitos tan especializados a los que la mayoría de los ciudadanos difícilmente pueden acceder por lo preciso y complejo del lenguaje en el que se formulan (leyes y normativas, contratos, documentos en el ámbito de la salud, instrucciones de uso...). Como señala la International Federation of Library Associations and Institutions (20I0) en su informe sobre Lectura Fácil "Proporcionar materiales de lectura fácil es una cuestión tanto de accesibilidad como de democracia. Los textos de lectura fácil, por tanto, están dirigidos tanto a personas con alguna discapacidad que tienen una necesidad permanente de este tipo de textos como a lectores con competencia lingüística limitada, que pueden necesitar recurrir a los mismos de modo temporal o en relación a temáticas concretas y particulares.

Partiendo de este reconocimiento, la iniciativa de Lectura Fácil tiene por objeto, generar textos, o traducir aquellos ya existentes, en un formato que permita la compresión de los mismos para la gran mayoría de la población. Para lograr esto se usarán recursos que varían desde una simplificación del lenguaje, al uso de ilustraciones o el empleo de estrategias concretas de maquetación de los textos.

Hay estudios internacionales que muestran que más del $25 \%$ de la población adulta en la mayoría de los países, y por diversas causas, no alcanza el grado de alfabetización o destreza 
lectora esperada después de la educación oficial. Para las empresas y organismos públicos debe ser por tanto una prioridad el hecho de que sus mensajes sean accesibles para todas las personas. Siendo, como se ha dicho, un derecho de todo ciudadano y ciudadana el comprender la información que se transmite, constituye una obligación de quién transmite el mensaje el hacerlo de manera comprensible. Por otro lado, es una fórmula rentable el hecho de que la información de nuestra empresa o institución llegue a un número mucho mayor de personas.

Por todo lo dicho, no cabe duda de que constituye una apuesta atrevida y un guiño hacia la innovación social el hecho de que un conjunto de entidades de la economía social se hayan embarcado en este mundo por explorar como es la accesibilidad cognitiva en general y la lectura fácil en particular. En esa tarea se encuentra el Instituto Lectura Fácil (www. institutolecturafacil.org), una institución de ámbito nacional cuyos fines principales son dos: reivindicar ante las administraciones la necesidad de hacer comprensibles los mensajes y, proporcionar al conjunto de organizaciones todo el proceso completo de adaptación, validación, edición y maquetación de textos en lectura fácil.

En esta ambiciosa meta que es la lectura fácil y la eliminación de las barreras de la comprensión, quedan muchos ámbitos por explorar, mucho conocimiento que generar. No obstante, estamos embarcados en un emocionante reto y animamos a aquellas organizaciones comprometidas con la igualdad de oportunidades a poner en marcha iniciativas que contribuyan a fomentar la accesibilidad cognitiva.

En esta lucha, desde el Instituto Lectura Fácil trabajamos bajo las premisas de: responsabilidad, independencia, permanencia y trascendencia, sostenibilidad, igualdad de derechos y respeto a la diversidad para ir de la mano en favor de las personas con especiales dificultades en la comprensión. Lo que se pretende, en definitiva, es poner en valor a las empresas y organismos públicos o privados que apuestan por la lectura fácil y ayudarles en esta tarea que contribuye a hacer una sociedad más democrática y comprometida con los valores constitucionales. 


\section{Referencias bibliográficas y normativas}

Asociación Internacional de Editores (I992). Carta para el Lector. (Texto aprobado en el XXIV Congreso de la Asociación Internacional de Editores). Comisión Internacional del Libro. UNESCO.

Centro de Referencia Estatal de Autonomía Personal y Ayudas Técnicas, CEAPAT. (2013) Cuestionarios de Vivienda (en línea). http:// www.ceapat.es/ceapat_oI/centro_documental/ accesibilidad/vivienda/IM_07288 .

España. Ley I3/I982, de 7 de abril, de integración social de los minusválidos. Boletín Oficial del Estado, núm. Io3, de 30 de abril de I982, pp. IIIO6 a IIII2.

España. Ley 26/20I I de I de agosto, de adaptación normativa a la Convención Internacional sobre los Derechos de las Personas con Discapacidad. Boletín Oficial del Estado, núm. I 84, de 2 de agosto de 20 I I, pp. 87478 a 87494 .

España. Ley 39/2006, de I4 de diciembre, de promoción de la autonomía personal y atención a las personas en situación de dependencia. Boletín Oficial del Estado, núm. 299, de 15 de diciembre de 2006, pp. 44I42 a 44I 56.

España. Ley 49/2007, de 26 de diciembre, por la que ese establece el régimen de infracciones y sanciones en materia de igualdad de oportunidades no discriminación y accesibilidad universal de personas con discapacidad. Boletín Oficial del Estado, núm. 3 IO, de 27 de diciembre de 2007, pp. 53278 a 53284 .

España. Ley 5I/2003, de 2 de diciembre, de igualdad de oportunidades, no discriminación y accesibilidad universal de las personas con discapacidad. Boletín Oficial del Estado, núm. 289 , de 3 de diciembre de 2003, pp. 43 I 87 a 43195 .

España. Real Decreto Legislativo I/20I3, de 29 de noviembre, sobre el Texto Refundido de la Ley General de derechos de personas con discapacidad y de su inclusión social. Boletín
Oficial del Estado, núm. 289, de 3 de diciembre de 2013 , pp. 95635 a 95673.

Fundación ONCE (2013). Pautas de diseño de pictogramas para todas las personas (en línea). http://accesibilidadcognitivaurbana. fundaciononce.es/docs/Manual_pictogramas. pdf.

García Moreno, D. (20I2). "Diseño de sistemas de orientación espacial: Wayfinding”. En VV.AA.: Accesibilidad universal y diseño para todos. Arquitectura y urbanismo. Madrid: Fundación Once.

Gete-Alonso, M.C. (20I3). "El estado civil y las condiciones de la persona”, En Gete-Alonso, M.C. (dir.) y Solé, J. (coord.): Tratado de Derecho de la Persona física. Navarra: Civitas Thonson Reuters, pp. 22I y ss.

International Federation of Library Associations and Institutions (2010). Guidelines for easyto-read materials. (IFLA Profesional Report I20). Non Published Manuscript. The Hague, Netherlands.

Naciones Unidas (2006). Convención Internacional sobre los Derechos de las Personas con Discapacidad (en línea). http://www.un.org/ spanish/disabilities/default.asp? $i d=497$. .

TECHNOSITE. (2009). Accesibilidad y Capacidades Cognitivas. Movilidad en el entorno urbano. Vol. I, Conocimiento y Experiencias. Madrid: Fundación Once.

UNAPEI, fédération d'associations française de représentation et de défense des intérêts des personnes handicapées mentales et de leurs familles (2010). Guide Pratique de l’Accessibilité (en línea). ‘http://www.unapei. org/IMG/pdf/GuideAccess.pdf.

UNESCO / IFLA (I994). Manifiesto de la Biblioteca Pública (en línea). http://www. unesco.org/webworld/libraries/manifestos/ libraman_es.html.

UNESCO / IFLA (I999) Manifiesto de la Biblioteca Escolar (en línea). http://www.unesco. 
org/webworld/libraries/manifestos/school_ manifesto_es.html.

Verdugo, M.A. (2003). “Análisis de la definición de discapacidad intelectual de la Asociación
Americana sobre retraso mental de 2002". Revista Española sobre discapacidad Intelectual. Vol. 34 (I). 205, 5-I9. 